\title{
5G Network Deployment in Nigeria: Key Challenges and The Way Forward
}

\author{
Cosmas Kemdirim Agubor, Nkwachukwu Chukwuchekwa and Longinus Sunday Ezema
}

\begin{abstract}
Many countries are faced with different challenges in the deployment of $5 \mathrm{G}$ mobile wireless communication technology. These challenges have delayed the smooth rollout of this technology in these countries. Nigeria has its own issues that have hindered the implementation of this technology in the country. This paper discusses these challenges and suggestions made on what to do for the implementation of 5G technology. A survey was done by visiting and obtaining reports from two major players in the industry as well as understudying actions taken by other nations in tackling similar problems related to $5 \mathrm{G}$ network implementation. Based on the information gathered both from the industry and related literature some useful suggestions such as improved fiber infrastructure and relaxing regulatory barriers to encourage investors were made as a way forward for the full implementation and operation of the $5 \mathrm{G}$ technology in Nigeria.
\end{abstract}

Index Terms - Edge computing, 5G network, optic fiber.

\section{INTRODUCTION}

Mobile wireless communication in Nigeria has evolved over the years. From the analog based technology of $1 \mathrm{G}$ (first generation) to the digital wireless systems of $2 \mathrm{G}$ (second generation), 3G (third generation) and the most recent and current $4 \mathrm{G}$ (fourth generation). The $2 \mathrm{G}$ technology uses TDM (Time Division Multiplexing) whereas 3G and 4G make use of WCDMA (Wideband Code Division Multiple Access) and OFDMA (Orthogonal Frequency Division Multiple Access) respectively. The $4 \mathrm{G}$ is a technology designed to be all-IP and to support mobility much more than the previous technologies [1]. In comparison, the key features of $4 \mathrm{G}$ over all others before it, are network detection and selection as well as seamless handover and service continuity [2]. Table I gives a comparative summary of the different digital mobile wireless technologies [3].

TABLE I: COMPARISON OF 2G, 3G AND 4G TECHNOLOGIES

\begin{tabular}{cccc}
\multicolumn{4}{c}{ TABLE I: COMPARISON OF 2G, 3G AND 4G TECHNOLOGIES } \\
\hline Features & $2 \mathrm{G}$ & $3 \mathrm{G}$ & 4G \\
\hline Access methodology & TDMA & WCDMA & OFDMA \\
Maximum downlink speed & $10-150 \mathrm{Kbps}$ & $384 \mathrm{Kbps}$ & $100 \mathrm{Mbps}$ \\
Maximum uplink speed & $10-150 \mathrm{Kbps}$ & $28 \mathrm{Kbps}$ & $150 \mathrm{Mbps}$ \\
Bandwidth & $200 \mathrm{KHz}$ & $5 \mathrm{MHz}$ & $1.4-20 \mathrm{MHz}$ \\
\hline
\end{tabular}

In Nigeria, despite the enhanced 4G technology already in use and due to the ever-increasing demand for bandwidth attention has now shifted to the next generation wireless technology - 5G network or IMT-2020 (5G). The

Submitted on July 28, 2020

Published on March 17, 2021.

Cosmas Kemdirim Agubor, Department of Electrical and Electronic

Engineering, Federal University of Technology, Owerri, Nigeria.

(e-mail: cosmas.agubor@futo.edu.ng)
International Mobile Telecommunication (IMT) 2020 standards is a name for the systems, components, and related elements that support enhanced capabilities beyond those offered by IMT-2000 (3G) and IMT-Advanced (4G) systems [4]. This technology is expected to improve on the performance of $4 \mathrm{G}$ by offering new applications for improved services. Apart from the expected improved quality of services (QoS) the $5 \mathrm{G}$ is also expected to bring about great revolution in the field of communication with improved signaling efficiency and coverage speed [5].

$5 \mathrm{G}$ in Nigeria will leverage on the successes of previous generations of mobile networks such as $2 \mathrm{G}, 3 \mathrm{G}$ and $4 \mathrm{G}$ mobile wireless networks and on the other hand proffer solutions to some of the short comings of 4G technology. Its key capabilities will be in areas such as spectrum efficiency, user experience data rate, latency, mobility, connection density, etc. [6]. It will result to a super-connected era of smart manufacturing, efficient transportation, improved medical services and improvement in the living standard of the people. Wireless Operators and other major players in the industry will capitalize on $5 \mathrm{G}$ as an opportunity to move beyond providing connectivity services to developing robust solutions and services for their numerous consumers in the country.

The next generation network will be advanced and upgraded to enable it to handle the weaknesses of existing technologies and new challenges. The network will be based on Cognitive Radio (CR) technology which is to act as a transceiver that matches and respond to the radio frequencies [5]. Unlike the traditional radio, the CR has the ability of cognitive intelligence. It can in real-time detect the nature of the environment and through adaptive change parameter settings for the study and decision-making, make full use of spectrum resources effectively [7].

The CR is expected to form part of the network architecture known as the Master Core network. The 5G is a convergence of technologies such as Parallel Multimode (PMM) technology, Cloud Computing (CC) and Cognitive Radio, upgradeable and based on All IP (Internet Protocol) platform [8]. System upgradability could be in both hardware and software.
Nkwachukwu Chukwuchekwa, Department of Electrical and Electronic Engineering, Federal University of Technology, Owerri, Nigeria. (e-mail: Nkwachukwu.chukwuchekwa ${ }^{\circledR}$ futo.edu.ng)

Longinus Sunday Ezema, Department of Electrical and Electronic Engineering, Federal University of Technology, Owerri, Nigeria.

(e-mail: longinus.ezemms ${ }^{\circledR}$ futo.edu.ng) 


\section{LITERATURE REVIEW}

Developmental issues affecting the roll out of $5 \mathrm{G}$ systems have been highlighted in many literatures. The capital expenses (CAPEX) for providing the required infrastructure and the security issues are some of the many concerns being raised. Some countries are projecting that by the end of 2019 challenges impeding deployment of $5 \mathrm{G}$ in their countries will be fully addressed giving way for the full implementation of the technology. One of such countries is India.

In [5], the problems of $5 \mathrm{G}$ implementation that have to be addressed in India was elaborately discussed. Lack of Regulatory bodies in India's Telecom sector, last mile connectivity and lack of fiber infrastructure are some of the major problems listed that may impede the deployment of $5 \mathrm{G}$ in that country. Low data speed and high rates in this country is another major issue that has to be handled. The paper proposed the use of mobile edge computing (MEC) as a solution to the implementation problem of $5 \mathrm{G}$ in India. Here, MEC was defined as the framework of the network with cloud computing features which provides information technology (IT) environment at the edge of the cellular network. This method improves performance of applications by reducing network congestion.

In Canada the regulation and cost structure faced by the Operators were the two major problems mentioned that Operators who are subject to Canadian regulation had to contend with [9]. These two interconnected and related variables - regulation and cost of deployment - remain the two greatest forces of drag in Canada. The UK is also in the race of $5 \mathrm{G}$ deployment but there are some challenges that have to be handled for a successful network implementation. These challenges were listed in [10] as specific barriers. They are legislation, access to spectrum, affordability of sites in both urban and rural areas, access to power, inconsistent approach by network providers, etc. These overreaching issues are seen as barriers that have to be tackled to pave the way for effective deployment of 5G technology in the UK.

Reports on the challenges faced by various European countries such as Denmark, Macedonia, Poland etc. are documented in [11]. In Denmark an advisory board was set up to look at such issues like spectrum, regulatory barriers and lower frequency charges for backbone radio links. To be explored are ways and methods $5 \mathrm{G}$ could bring or contribute to the economic growth and productivity of the nation. In the same report the Republic of Macedonia showed concern on existing regulation. There was need to further study and modify existing regulation that will not only allow permission for the construction of $5 \mathrm{G}$ infrastructure but will also give special attention to simplifying regulation of small cell. The report on the Republic of Poland centered on an agreement known as "5G for Poland" which was signed in 2017. By this agreement, the parties involved were to ensure the smooth implementation of $5 \mathrm{G}$ in the country. For this to be successfully achieved several problems have to be solved some of which are

(i) Speeding and improving the investment process;

(ii) Infrastructure maintenance cost reduction;

(iii) Availability of radio spectrum;

(iv) Review of existing regulations;

(v) Ensuring network security.
The significance of this paper is to draw attention of the Nigerian government on the physical and technical challenges impeding the rollout of 5G technology and the steps to address them. Industrial visit was made to obtain information from the field. Relying on literature also, methods used by other nations in solving problems similar to that facing Nigeria were suggested.

The novelty of this paper is that only problems peculiar to Nigeria are presented in a more comprehensive manner for the first time. Information from both industry players and the regulating body is captured and discussed holistically as a way forward towards the full implementation of $5 \mathrm{G}$ technology.

\section{5G DEPLOYMENT IN NIGERIA}

Nigeria like many other nations is in the race of being one of the early birds for the deployment of 5G technology. A successful implementation of this technology will not only usher an array of improvements in internet connectivity in the country where broadband penetration is still low but will provide an era of new and emerging technologies such as Internet-of-Things (IoT), Artificial Intelligence (AI) and Big Data to improve lives and standard of work. The Nigerian Communication Commission (NCC) which is the regulating body has a policy of maintaining neutrality in the choice of technology to be adopted by the various service providers. Although a three-month trial test approved in November 2019 has been conducted, the technology itself has not been launched for commercial use [12].

\section{A. Challenges}

Nigeria is pushing to rollout of $5 \mathrm{G}$ network. However, just like other countries mentioned above there are challenges that may impede its successful implementation. These challenges are discussed below.

1) Poor Fiber Penetration: The coverage of optic fiber cable in Nigeria is not encouraging especially in cities where $5 \mathrm{G}$ is expected to be initially deployed. This poor penetration of fiber optics is even worse in most suburban and rural areas. According to the NCC report released in 2018, metropolitan cities need over $120,000 \mathrm{~km}$ of fiber networks for the country's backhaul interconnectivity. Unfortunately, only about $32 \%$ of this requirement has been met leaving a deficit of $68 \%$. Some of the major causes of poor fiber infrastructure are:

i) Right of Way (RoW): This is purely an administrative issue that has to do with existing policies of the Federal, State and Local Governments. In most cases acquisition of RoW is cumbersome, expensive, and very discouraging to investors [13].

ii) Cable vandalism: This is common during road construction and maintenance. Existing cable routes are frequently destroyed during road construction causing network downtime and rise in maintenance cost. Efforts and funds which would have been used to expand existing network are diverted in cable network maintenance. This culture of optic fiber cable vandalism arises from the fact that there is poor documentation and planning by the appropriate government authorities and the fiber cable routes lack indicators to guide road construction companies. This has made a greater number 
of cell sites to be connected through microwave backhaul instead of optic fiber cable.

2) Device Challenges: The deployment of 5G technology is determined by the availability of $5 \mathrm{G}$ devices which are presently very scarce due to some technical challenges. These design challenges include multiband support of upper and lower frequency bands. There is also heating concerns as a result of power consumption needed to transmit in high frequency bands [14].

3) Health Concerns: It is believed by many Nigerians that $5 \mathrm{G}$ network will impact negatively on their health. It has also been rumored that the present COVID-19 pandemic was caused by $5 \mathrm{G}$ technology in countries where this technology has undergone test trials. The fear is rooted on the fact that the network will be made up of several radiating communication antennas located approximately $100 \mathrm{~m}$ apart and capable of radiating high power electromagnetic waves. As a result of this concern the Nigerian Senate (a legislative arm of the Federal Republic of Nigeria) moved a motion to suspend the deployment and installation of the network in the country [15].

4) Network Security: Modern communication networks continue to evolve with cross-industry transformation such as IoT and Industry 4.0 leading to numerous types of devices and smartphones which are connected with broader set of applications. These will make the network vulnerable thus exposing it to new dimensions of attack. According to the Global Cyber Security Index (GCI) 2018 report released by the International Telecommunication Union (ITU), Nigeria ranked $57^{\text {th }}$ out of 175 countries listed in the campaign against the menace of cybercrime globally [16]. This shows that Nigeria's level of commitment in the fight of cybercrime is ranked medium. With $5 \mathrm{G}$ fully operational in the country like Nigeria that has a poor cybersecurity strategy unlike developed countries, it is likely that cybercrime will be in the increase.

5) Spectrum Pricing and harmonization: In Nigeria Telecommunication consumers bear the burden of high spectrum pricing. This according to reports is three times higher than the developed countries. This is one of the major roadblocks to broadband penetration in the country especially in the suburban and rural areas as government seek to maximize their revenue generation from spectrum licensing. Global harmonization of spectrum across different frequency bands demand coordinated efforts from global community and regional telecommunication bodies. Some spectrum appropriate for high capacity, network densification and ultra-high speed required for $5 \mathrm{G}$ network may already be in use. This challenge accounts for radio frequency interference along borders, international roaming issues, and high equipment cost. The harmonization issue is a big challenge for national regulatory bodies such as NCC in deploying and operating 5G network successfully.

6) Cost of Equipment and Service Availability: The current exchange rate of the country's local currency is very high. Telecommunication service providers in the country depend on foreign vendors for their equipment. This indicates that procuring and deploying this technology at the current exchange rate will be at a very high cost and this will be a heavy burden for the operators alone to bear. The huge investment required may prolong rollout time and service availability.

7) Poor Electrical Power Supply: The higher density 5G network brings new power supply demands. This increase in energy consumption is as a result of additional equipment and $5 \mathrm{G}$ sites or base stations necessary for high density coverage. Nigeria has been experiencing power inadequacies over the years. This age long crises in the power sector in Nigeria has not only contributed to the poor QoS but has hindered network expansion into the rural areas as well as increase in the operational cost on network Operators.

8) Poor Civil Infrastructure: This includes unplanned highways, bridges, rural roads, canals and utilities. These structures lack the provision for common Telecommunication Infrastructure resources such as ducting and power junction boxes to support $5 \mathrm{G}$ facilities.

\section{B. Way Forward}

1) Spectrum for 5G: To reap the benefits of $5 G$ there should be availability of spectrum. The first line of action for the development of $5 \mathrm{G}$ in Nigeria should be to establish spectrum policy that will guide the allocation of spectrum to major players in the industry. The NCC has reserved $26 \mathrm{Gz}, 38 \mathrm{GHz}$ and $42 \mathrm{GHz}$ spectrum to be allocated for $5 \mathrm{G}$ in the country [17]. The allocation of these frequencies to service providers should be in two stages-the allocation and assignment stages for effective rollout of the network by each provider.

2) Trial Test: The regulator should allow trial tests to be carried out at the reserved or proposed frequencies by all the service providers in the country. This is to ascertain the security and health concerns. Security and health agencies should be involved in these tests for the purpose of assisting the regulating body accordingly. This will help to develop a high level of cybersecurity of the network. It will also assist in developing the right regulatory standards and platform for effective rollout of the technology.

3) Investment Environment for 5G Network: In some countries like Canada 5G deployment is estimated to cost about $\$ 26$ billion. Therefore, to support the investment efforts of the Mobile Operators, a pricing policy that Operators would have to pay which at the long run will not have any negative impact on their investments should be used at auctions. The reason for this is that $5 \mathrm{G}$ networks involves huge investment in technology and any form of palliatives to the investors will serve as an encouragement.

4) Improved Fiber Infrastructure: For $5 \mathrm{G}$ implementation in Nigeria the role of improved Fiber network is very important. Instead of increasing the cost of RoW, State and Local governments should assist Telecom providers by giving RoW waivers and provision of tax incentives. This will encourage massive rollout of fiber infrastructure which can be used as a backhaul infrastructure due to its high reliability and ability to deliver ultra high capacity traffic.

5) Creating Enabling Environment: The government should play a greater role in encouraging investors to invest in the industry with less constraints. The issue of insecurity in the country should be tackled. This will aid a rapid rollout and commercialization of $5 \mathrm{G}$ technology in the country. Currently the number of base stations (BS) in the country is 39,000 [18]. 5G will need more BS than is available, therefore many more BS can be installed if investors are allowed to 
play more aggressively in the industry without fear of insecurity or economic barriers.

6) Mobile Edge Computing: Mobile Edge Computing (MEC) or Edge Computing is a feature of cloud computing which helps to reduce traffic congestion thus improving performance. The Edge Computing provides high bandwidth, low latency, and device processing such as IoT services, trusted computing and storage. The additional solutions Edge Computing provides makes MEC a fundamental part of $5 \mathrm{G}$ infrastructure. This technology can be hosted and managed by other types of service providers other than already existing communication service providers. Encouraging investors to compete with existing service providers for the operation of this technology will result to rapid expansion of the $5 \mathrm{G}$ technology nationwide.

7) Regulatory Barriers from Local Authorities: $5 \mathrm{G}$ rollout throughout the country will involve the use of small cell technology. Small cells have all the same characteristics of a BS. This technology uses low-power, short range $(10 \mathrm{~m}$ to $2.5 \mathrm{Km}$ ) wireless transmission systems. This feature makes this technology suitable for wider geographical coverage. In some countries excessive financial obligations on Operators have slowed implementation of small cells. Such barriers include unreasonable aesthetic restrictions, prolonged permitting processes and prohibitions on small cell placement. Such should be avoided in Nigeria to allow costeffective rollout of small cells especially in the big and industrialized cities like Lagos, Abuja, PortHarcourt and Kanu where $5 \mathrm{G}$ services are initially expected to be in high demand.

8) Improved Power Supply: Small cell technology is part of the $5 \mathrm{G}$ network. These numerous small cells will result to a high increase in demand of electric power supply. Operating small cells using electric power generating plants will result to increase in the operational expenses (OPEX). Therefore, the availability of steady power supply is a necessity for seamless provision of $5 \mathrm{G}$ services.

\section{CONCLUSION}

Many countries have had different challenges that have delayed the implementation and operation of the $5 \mathrm{G}$ technology. Some have solved these problems and others are still in the process. Nigeria is one of such countries that are yet to deploy this technology. This paper has succeeded in bringing to the fore some of the challenges that will likely prevent early rollout of $5 \mathrm{G}$ technology in the country. These challenges have been well explained. In order to deploy $5 \mathrm{G}$ wireless technology in Nigeria these key challenges must be overcome. Practical solutions obtained from the field have been suggested as ways to overcome these challenges leading to the full deployment of this technology. It is hoped that if these challenges are addressed, 5G deployment and operation in Nigeria will be a success.

\section{REFERENCES}

[1] C.K. Agubor, E.E. Atimati and A.O. Akande, "5G Wireless Network Mobility Management and Security Issues: An Overview of Existing Technologies,” Futo Journal Series, vol.4, No.2, pp.84 - 93, 2018.

[2] B. Bhattacharyya and S. Bhattacharya, "Emerging Fields in 4G Technology, its applications and beyond-An Overview," International
Journal of Information and Computation Technology, vol.3, no.4, pp.251-260, 2013.

[3] P.A. Ochang P.J. Irving, (August 2020) "Evolution Analysis of GSM UMTS and LTE Mobile Network Architectures, World Scientific News," Available online: www.worldscientificnews.com, Accessed: $8^{\text {th }}$ August 2020

[4] Setting the Scene for 5G: Opportunities \& Challenge, ITU Report 2018 Available online: www.itu.int $>5 \mathrm{~g}$-opportunities.... Accessed: $11^{\text {th }}$ February, 2020.

[5] S. Shivansh, "Problems in Implementing 5G in India and Solutions for it," Proceedings of 40th IRF International Conference, Bengaluru, India, 2018

[6] J. Banister, "5G Challenges for Network Deployment," Obitage, 2016

[7] T. Long and W. Juebo "Research and Analysis on Cognitive Radio Network Security," Wireless Sensor Network, vol. 4, pp.120-126, 2012.

[8] D. V. Aman and D. Shivani., "Convergence of 5G Technology by Using Distributed System," International Journal of Computer Science and Information Technologies, vol. 5, pp. 1223-1226, 2014.

[9] P. Burbank, "A Spectrum of Opportunities and Challenges: Canada's 5G Future, Available online: www.fasken.com/en/knowledge/2019, Accessed: $5^{\text {th }}$ January, 2020.

[10] D. Guy D. "UK faces serious $5 \mathrm{G}$ deployment challenges," TelecomTV Where Telecom Connect, 2018

[11] 5G Implementation in Europe and CIS, "Strategies and Policies Enabling New Growth Opportunities," Report on the ITU-Study Groups related Experts' Knowledge Exchange, pp. 1-13, 3-5 July 2018

[12] Nigerian Communication Commission Denies 5G Claims-Developing Telecoms. Available: www.developingtelecoms.com. Accessed: $10^{\text {th }}$ July, 2020.

[13] E.O. Agboje, S.O. Adedoyin, C.U. Ndujiuba, "State of Fibre Optic Networks for Internet Broadband Penetration in Nigeria- A Review," International Journal of Optoelectronic Engineering, vol.7, pp.1-12, 2017.

[14] I. Contanis, (August 2019), "5 critical 5G Network Deployment Challenges." Available: www.infovista.com. Accessed: $19^{\text {th }}$ June, 2020.

[15] A. Iyande, "Senate Seeks to Investigate 5G Network in Nigeria." Available: www.venturesafrica.com. Accessed: $15^{\text {th }}$ July, 2020.

[16] A.J. Akindele, (July 2019), "Fight against Cybercrime: Nigeria ranked $57^{\text {th }}$ globally," Available: www.premiumtimesng.com, Accessed: $20^{\text {th }}$ July 2020.

[17] C. Awaja, (September, 2019), NCC Reserves Spectrum for 5G Ahead of Network. Available: www.allafrica.com>stories, Accessed: $15^{\text {th }}$ July, 2020.

[18] J. Akiyode-Lawanson, (December 2019), "NCC sets the Scene for 5G Deployment in Nigeria," 2019. www.businessday.ng, Accessed: $15^{\text {th }}$ May, 2020. 